\title{
Association between ACE gene I/D polymorphisms and hyperandrogenism in women with Polycystic Ovary Syndrome (PCOS) and controls
}

\author{
Jing sun ${ }^{\dagger 1}$, Haijian fan ${ }^{\dagger 1}$, Yena Che ${ }^{1}$, Yunxia Cao*1,2, Xiaoke $\mathrm{Wu}^{3}$, Hai- \\ xiang Sun ${ }^{1}$, Fengjing Liang ${ }^{1}$, Long $\mathrm{Yi}^{1}$ and Yong Wang ${ }^{* 1}$
}

Address: ${ }^{1}$ Jiangsu Key Laboratory of Molecular Medicine \& The reproductive medicine Center of Drum Tower Hospital, Medical School of Nanjing University, Nanjing 210093, PR China, ${ }^{2}$ Department of Obstetrics and Gynecology, Anhui Medical University, Hefei 230022, PR China and ${ }^{3}$ Department of Obstetrics and Gynecology, The First Affiliated Hospital, Heilongjiang University of Chinese Medicine, Harbin 150040, PR China

Email: Jing sun - sjnju@163.com; Haijian fan - nju_fhj@163.com; Yena Che - yunye_525@yahoo.com.cn;

Yunxia Cao* - caoyunxia6@126.com; XiaokeWu - xiaokewu@nju.edu.cn; Hai-xiang Sun - stevensun@sohu.com;

Fengjing Liang - qqg149@sina.com; Long Yi - yilong@nju.edu.cn; Yong Wang* - yongwang@nju.edu.cn

* Corresponding authors †Equal contributors

Published: 14 July 2009

BMC Medical Genetics 2009, 10:64 doi:10.1186/1471-2350-10-64

This article is available from: http://www.biomedcentral.com//47I-2350/10/64

(C) 2009 sun et al; licensee BioMed Central Ltd.

This is an Open Access article distributed under the terms of the Creative Commons Attribution License (http://creativecommons.org/licenses/by/2.0), which permits unrestricted use, distribution, and reproduction in any medium, provided the original work is properly cited.
Received: 22 December 2008

Accepted: 14 July 2009

\begin{abstract}
Background: I/D polymorphisms of ACE are associated with the plasma ACE concentration. The ACE is associated with the angiogenesis of ovarian endothelium in vitro as well as steroidogenesis and follicular growth in cattle. Since ACE induces a high blood supply and hypersteroidogenesis in the ovary, it may be associated with polycystic ovary syndrome (PCOS) which exhibits hyperplasia, hypervascularity of the ovarian theca interna and stroma, as well as disorderd steroidogenesis. Therefore, we hypothesized that the ACE plays some roles in the human ovary. To investigate whether the ACE I/D polymorphisms are associated with the steroidogenesis disorder in PCOS and contribute to the susceptibility of PCOS in Chinese women, we designed a case-controlled association study in 582 individuals.

Methods: The ACE I/D polymorphisms were assessed in 582 reproductive-age women. Genotyping and frequency of ACE I/D polymorphisms were obtained by PCR amplification that was performed on genomic DNA isolated from blood leucocytes. Results were analyzed in respect to clinical test results.

Results: The frequencies of the D allele and the genotypic distributions (DD, ID and II) in the women with PCOS did not differ from those in controls $(P=0.458)$. However, there were significant differences in the concentrations of testosterone among three genotypes both in the PCOS patients and controls $(P$ $=0.0045, P=0.0052$, respectively). Differences were also found between these groups with distinct genotypes: DD versus II and DI versus II in the PCOS patients as well as DD versus DI and DD versus II in the controls. There were significant differences in the ratio of LH/FSH among three genotypes in the patients $(P=0.0 \mathrm{I})$. However, there were no statistical differences in the BMI, AAM, E2 concentrations and other serum hormone concentrations among the three genotypes both in the PCOS patients and controls.

Conclusion: The ACE I/D polymorphisms were not associated with the pathogenesis of PCOS. However, the polymorphisms were associated with the steroidogenesis in the ovary. The observation indicated that the ACE I/D polymorphisms were not the key etiological factor, which in stead may be associated with the aggravated clinical manifestations of PCOS.
\end{abstract}




\section{Background}

There is evidence to indicate that the RAS may influence oocyte maturation, ovulation and steroidogenesis as well as formation of corpus luteum through complex interactions with other systems [1]. ACE, encoded by the ACE gene, is one of the components of RAS and can be expressed in multiple tissues including ovaries [2]. In addition to the important role in regulating blood pressure, the ACE and its products are associated with the angiogenesis of ovarian endothelium in vitro [3] and the resumption of meiosis [4,5], steroidogenesis [6], and follicular growth [7] in cattle. However, there are few reports on the roles of ACE in human ovaries. Rigat et al [8] demonstrated that the inter-individual variability of the plasma ACE concentration is associated with an insertion (I)/deletion (D) polymorphism involving a 287-bp DNA sequence situated in intron 16 of the ACE gene, the socalled ACE I/D polymorphism. Thus researchers use the I/ D polymorphism as a valid marker for studying the associations between the ACE gene polymorphism(s) and pathophysiological conditions.

PCOS, present in $5 \%-10 \%$ of reproductive-age women, is a constellation of hyperandrogenism, hyperinsulinism $[9,10]$, menstrual dysfunction, and associated metabolic and cardiovascular complications [11]. It is postulated that the environmental and genetic factors contribute to the etiology of PCOS [12]. During the past decades, the roles of more than 70 candidate genes have been evaluated for causal roles in PCOS; however, because of genetic and phenotypic heterogeneity and underpowered studies, the results of many of these studies remain inconclusive.

Patients with PCOS not only have the clinical characteristics of oligomenorrhoea, hirsutism, infertility and hyperinsulinemia but also exhibit obesity, hypertension, dyslipidemia, and an increased pro-thrombotic state $[10,11]$. They also have an increased risk of type2 diabetes [13], impaired glucose tolerance and cardiovascular diseases. Hyperplasia and hypervascularity of the ovarian theca interna and stroma are also the prominent features of PCOS, a leading cause of infertility [14]. As an impor- tant regulator of blood pressure, ACE may play a potential role in the progress of the cardiovascular diseases in the patients with PCOS. In addition, the product of the ACEAngiotensin II plays a role in angiogenesis during ovulation, the formation of the corpus luteum, and luteolysis in cattle [15]. Early studies using pharmacologic approaches indicated that receptors for angiotensin II are present on steroidogenic cells which can synthesize steroid hormones [1]. Experimental studies found that the presence of the $\mathrm{D}$ allele is associated with higher levels of plasma ACE [8]. The higher levels of plasma ACE probably leads to a higher level of Ang-II and the disorder of the steroid hormone synthesis. To investigate whether the ACE genotype is associated with the abnormal levels of hormones in PCOS patients, we designed a case-control experiment including 346 PCOS patients and 236 non-PCOS individuals as controls.

\section{Methods \\ Subjects}

A total of 582 women were studied. 346 of them were patients with PCOS and 236 were non-PCOS women as controls. The controls were selected by excluding the diagnosis of PCOS according to the 2003 Rotterdam Criteria and exhibiting normal menstrual cycles ( $<32$ days). All the individuals in the control group were without obesity, hirsutism (the F-G hirsutism score $\geq 7$ ), acne, or overmuch sebum. All the women recruited for the study were from the Chinese Han ethnic group. The study was approved by Medical School of Nanjing University, and informed consent was obtained from every study participant.

\section{PCOS diagnostic criteria and hormone measurements}

Patients with PCOS were diagnosed by the 2003 Rotterdam Criteria [16]. The Rotterdam Criteria requires at least two of the following indicators for diagnosis of PCOS: clinical or biochemical signs of hyperandrogenism (Table 1), oligomenorrhea or amenorrhea, and presence of polycystic ovarian (PCO) morphology on ultrasound (Table 1 ), with the exclusion of other causes of hyperandrogenism such as hyperprolactinemia, androgen-secreting tumors, Cushing's syndrome and nonclassic congenital

Table I: The criteria of clinical/biochemical hyperandrogenism and PCO

\begin{tabular}{lll}
\hline Clinical features $\quad$ Hirsutism & $\begin{array}{l}\text { There're pelages around anocheilon, lower mandible, areola mammae and } \\
\text { the midline of inferior belly etc. Note:Although some patients have acnes, } \\
\text { our gynecologists mainly rely on the hirsutism as the clinical features of } \\
\text { hyperandrogenism. }\end{array}$ \\
\hline Biochemical indices $\quad$ Total testosterone $(\mathrm{T})$ in the serum (nmol/L) & $\begin{array}{l}\text { Normal: }<1.4 \text {; Hyperandrogenism: }>1.4 \\
\text { (during the third to the fifth day of the menstrual cycle) }\end{array}$ \\
\hline The criteria of PCO & $\begin{array}{l}\text { I. The follicular phase ovary lacking follicles larger than } 10 \mathrm{~mm} \text { in diameter } \\
2 . \text { The presence of } 12 \text { or more follicles measuring } 2-9 \mathrm{~mm} \text { in diameter, or } \\
\text { increased ovarian volume }(>10 \mathrm{~mL})\end{array}$
\end{tabular}


adrenal hyperplasia. We calculated the body mass index (BMI = body weight in kilograms divided by square of height in meters) to assess obesity. The peripheral blood was obtained by a single venipuncture during the $3 \mathrm{rd}$ to the 5th day of the menstrual cycle for those who had menstruation and at any time for those who had amenorrhea. All peripheral blood samples were obtained between 8 $\mathrm{AM}$ and $9 \mathrm{AM}$ after a 12-hour overnight fast. None of the study participants had been taking hormonal medications, including contraceptive pills, for the previous three months before the hormone measurement. Blood samples were immediately centrifuged, and then serum was separated and frozen at $-80^{\circ} \mathrm{C}$ until assayed. Levels of total testosterone (T), follicle-stimulating hormone (FSH), luteinizing hormone (LH), total testosterone (T), and estradiol (E2) in the sera were measured by RIA (Beijing Northern Institute of Biological Technology of China and the CIS Company of France). The intra- and interassay coefficients of variation of all the assays were less than $10 \%$.

\section{Polymorphism genotype analysis}

Genomic DNA was extracted from venous blood samples using Chelex ${ }^{\otimes}-100$ as a medium (Promega, Madison, WI, USA). For each subject, the presence (allele I) or absence (allele D) of the 287-bp Alu repeat in intron 16 of the ACE gene was determined by measuring the size of DNA fragments after polymerase chain reaction (PCR) amplification. The PCR conditions were as described by Brigitte Rigat et al. [17], using a primer pair of 5'-CTG GAG ACC ACT CCC ATC CTT TCT-3' (sense oligo) and 5'-GAT GTG GCC ATC ACA TTC GTC AGA T-3' (anti-sense oligo). PCR amplification was carried out in a total volume of $25 \mu \mathrm{L}$ containing 50 ng template DNA, 10 pmols of each primer, $2.5 \mu \mathrm{L}$ STR (short tandem repeat) $10 \times$ buffer (STR $10 \times$ buffer, Promega, Madison, WI, USA) and $1.5 \mathrm{U}$ of Taq DNA polymerase (Promega, Madison, WI, USA). The PCR was performed in a PTC-100 (MJ Research ${ }^{\mathrm{TM}}$, Incorporated) thermocycler as follows: An initial denaturation step of 2.5 minutes at $94^{\circ} \mathrm{C}$, then 30 cycles consisting of 30 seconds of denaturation at $94^{\circ} \mathrm{C}, 105$ seconds of annealing at $60^{\circ} \mathrm{C}$, and 1.5 minutes of extension at $72^{\circ} \mathrm{C}$. The PCR products were separated on a $2 \%$ agarose gel, and DNA was visualized by ethidium bromide staining (Figure 1). The expected PCR product was a 190-bp fragment in the presence of the deletion (D) allele and a 490bp fragment in the presence of the insertion (I) allele. Thus, each DNA sample revealed one of three possible patterns after electrophoresis: a 490-bp band (genotype II), a 190-bp band (genotype DD), or both 490-and 190bp bands (genotype ID).

\section{Statistical analysis}

The frequencies of ACE alleles and genotypes among the patients and controls were obtained by direct enumera-

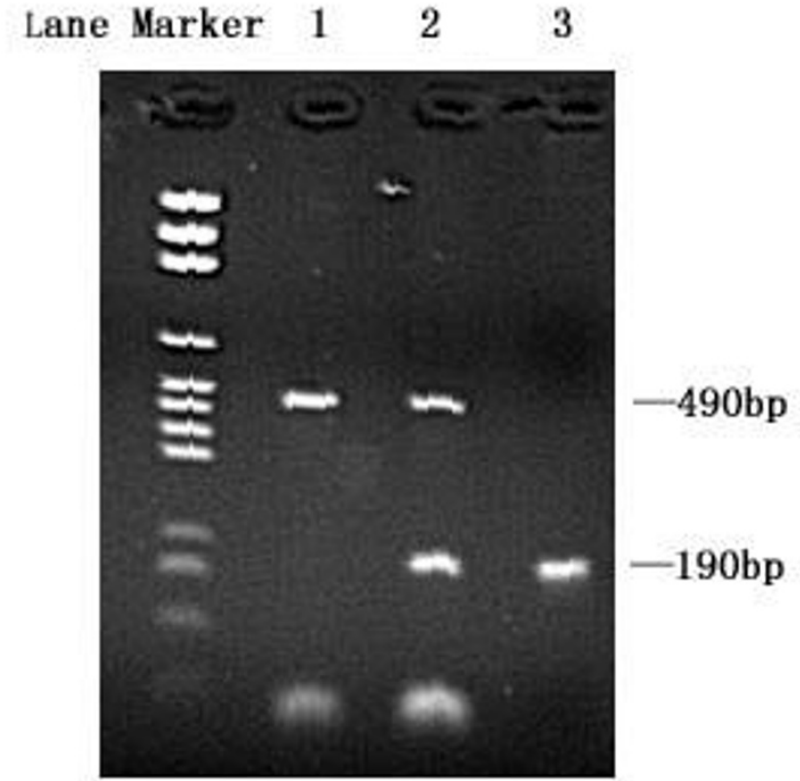

Figure I

PCR detection of the I/D polymorphism of the ACE gene (lanes I-3). PCR conditions were as described by Brigitte Rigat et al [ I I]. 2\% agarose gel electrophoresis, ethidium bromide staining and UV transillumination were performed. Lane Marker: DNA marker. Lane I: Band of 490 bp indicating genotype II; Lane 2: Bands of 490 bp and 190 bp indicating genotype I/D; Lane 3: Band of $190 \mathrm{bp}$ indicating genotype DD.

tion based on the PCR results, and the deviation from Hardy-Weinberg equilibrium was evaluated using the $\chi 2$ test. Genotypic distributions between the patients and controls were compared by $\chi 2$-test of the $2 \times 3$ tables. The analysis was performed using the SAS system software (SAS Institute Inc., Cary, USA). The results of serum hormone levels were reported as MEANS $\pm \mathrm{SD}$. The regression and correlation tests were used to analyze the association of age or BMI and the concentrations of the hormone. Differences in serum hormone levels among different genotypic individuals were assessed by using one way analysis of variance (ANOVA). Tukey-test was used for further analysis of the differences among the three genotypes, which was performed using the SAS system software. P < 0.05 was considered statistically different.

\section{Results}

The overall characteristics of the PCOS patients and the controls were presented in Table 2. There were no correlations between the age or BMI and the concentrations of the hormone. The frequencies of $\mathrm{D}$ allele were $51.45 \%$ and $55.3 \%$ in the patients $(\mathrm{n}=346)$ and the controls $(\mathrm{n}=$ 
Table 2: The overall characteristics of PCOS patients and controls

\begin{tabular}{|c|c|c|c|c|c|c|c|c|c|}
\hline - & $\mathrm{N}$ & Age (years) & AAM (years) & BMI $\left(\mathrm{kg} / \mathrm{m}^{2}\right)$ & FSHIU/L & LHIU/L & $\mathrm{LH} / \mathrm{FSH}$ & $\mathrm{T}(\mathrm{nMol} / \mathrm{L})$ & E2 (pMol/L) \\
\hline PCOS & 346 & $26.49 \pm 4.0^{*}$ & $14.57 \pm 1.62$ & $22.80 \pm 3.79 *$ & $\begin{array}{l}8.14 \pm 5.9 I^{*} \\
(\mathrm{~N}=325)\end{array}$ & $\begin{array}{l}20.39 \pm 20.3^{*} \\
(N=325)\end{array}$ & $\begin{array}{l}2.63 \pm 1.33^{*} \\
(\mathrm{~N}=325)\end{array}$ & $\begin{array}{l}4.04 \pm 4.12^{*} \\
(\mathrm{~N}=325)\end{array}$ & $\begin{array}{l}226.92 \pm 117.04^{*} \\
(\mathrm{~N}=325)\end{array}$ \\
\hline Control & 236 & $31.64 \pm 4.35$ & $14.75 \pm 2.66$ & $21.32 \pm 2.32$ & $\begin{array}{l}6.97 \pm 2.16 \\
(\mathrm{~N}=219)\end{array}$ & $\begin{array}{l}4.55 \pm 2.16 \\
(N=219)\end{array}$ & $\begin{array}{l}0.67 \pm 0.33 \\
(\mathrm{~N}=219)\end{array}$ & $\begin{array}{l}\mathrm{I} .6 \pm 3.82 \\
(\mathrm{~N}=219)\end{array}$ & $\begin{array}{l}17 \mid .64 \pm 140.68 \\
(N=219)\end{array}$ \\
\hline
\end{tabular}

Note: $* P<0.05$ vs control. We failed to assay the hormone levels in several women with PCOS and controls.

236), respectively. In all the 582 study subjects, the ACE genotypic distributions were $28.32 \%$ (DD), $46.24 \%$ (ID), 25.43 (II) in the patients, and $32.63 \%$ (DD), $45.34 \%$ (ID), $22.03 \%$ (II) in the controls, respectively. In both the patient and control groups the genotypic distributions were in agreement with Hardy-Weinberg equilibrium $(\chi 2$ $=1.914$ and 1.623 , respectively, $P>0.05)$. No significant difference was observed in the frequency of the genotypic distributions between the patients with PCOS and the non-PCOS controls $(P=0.458)$ (Table 3$)$.

\section{Data analysis}

By ANOVA analysis, we observed significant differences in the concentrations of testosterone among three genotypes in both the patients and the controls $(P=0.0045, P=$ 0.0052, respectively) (Table 3 ). Further analysis (Tukey) showed statistical differences $(P<0.05)$ between these groups with distinct genotypes: DD versus II and DI versus II in the PCOS patients as well as DD versus DI and DD versus II in the controls. In both patients and controls, the concentration of testosterone in the DD genotype was higher than that in the II genotype. Significant differences were also found in the ratio of LH/FSH among the three genotypes in the patients $(P=0.01)$. In contrast, no statis- tical differences in the concentration of estradiol (E2) were observed among the three genotypes in both patients and the controls (Table 3). We found no statistical differences of the BMI, AAM and other serum hormone concentrations among different genotypes in patients and controls.

\section{Discussion}

In this case-control study the D allele of the ACE gene had no influence on the occurrence of PCOS. No significant differences were observed in the distribution of the genotypes between the patients and the controls. Regardless of the criterion used for assessing patients of PCOS (oligomenorrhea or amenorrhea; presence of polycystic ovarian (PCO) morphology on ultrasound, and clinical or laboratory evidence of hyperandrogenism), no differences were observed among the three genotypes. These results suggested that the $\mathrm{D}$ allele of the ACE gene was not a major etiological factor for PCOS. Our current finding is contrary to the observation reported by Yunxia Cao et al $[18,19]$ in a smaller sample, which suggests that the D allele is associated with the enhanced RAS and the formation of polycystic ovary and hyperandrogen. Several possibilities may account for this discrepancy: first, the

Table 3: Anthropometric characteristics and serum hormone concentrations in women with different genotypes

\begin{tabular}{|c|c|c|c|c|c|c|c|c|}
\hline \multirow[t]{2}{*}{$A C E$ genetype } & \multicolumn{3}{|l|}{ PCOS } & \multirow[b]{2}{*}{$P$} & \multicolumn{3}{|l|}{ CONTROL } & \multirow[b]{2}{*}{$P$} \\
\hline & DD & ID & ॥ & & DD & ID & II & \\
\hline $\mathrm{N}$ & 98 & 160 & 88 & _ & 77 & 107 & 52 & $0.458^{a}$ \\
\hline Frequency (\%) & 28.32 & 46.24 & 25.43 & & 32.63 & 45.34 & 22.03 & \\
\hline Age (years) & $26.63 \pm 3.86$ & $26.31 \pm 4.16$ & $26.93 \pm 3.69$ & 0.75 & $32.62 \pm 3.43$ & $31.63 \pm 4.45$ & $31.15 \pm 4.66$ & 0.38 \\
\hline AAM (years) & $14.43 \pm 1.77$ & $14.66 \pm 1.61$ & $14.44 \pm 1.45$ & 0.67 & $15.23 \pm 3.73$ & $14.59 \pm 1.52$ & $14.63 \pm 2.76$ & 0.58 \\
\hline BMI $\left(\mathrm{kg} / \mathrm{m}^{2}\right)$ & $22.12 \pm 3.23$ & $23.15 \pm 4.02$ & $22.55 \pm 3.66$ & 0.33 & $20.75 \pm 2.06$ & $21.49 \pm 2.46$ & $21.48 \pm 2.33$ & 0.37 \\
\hline FSH (IU/L) & $\begin{array}{l}8.22 \pm 5.00 \\
(N=92)\end{array}$ & $\begin{array}{l}7.91 \pm 4.5 \\
(N=|5|)\end{array}$ & $\begin{array}{l}8.83 \pm 10.25 \\
(N=83)\end{array}$ & 0.77 & $\begin{array}{l}6.7 \pm 2.87 \\
(N=72)\end{array}$ & $\begin{array}{l}7.52 \pm 2.3 \\
(\mathrm{~N}=99)\end{array}$ & $\begin{array}{l}6.67 \pm 1.49 \\
(N=48)\end{array}$ & 0.13 \\
\hline LH (IU/L) & $\begin{array}{l}20.94 \pm 21.53 \\
(N=92)\end{array}$ & $\begin{array}{l}21.98 \pm 22 \\
(N=151)\end{array}$ & $\begin{array}{l}13.96 \pm 7.33 \\
(\mathrm{~N}=83)\end{array}$ & 0.19 & $\begin{array}{l}4.68 \pm 2.57 \\
(N=72)\end{array}$ & $\begin{array}{l}4.77 \pm 1.94 \\
(\mathrm{~N}=99)\end{array}$ & $\begin{array}{l}4.31 \pm 2.12 \\
(\mathrm{~N}=48)\end{array}$ & 0.55 \\
\hline LH/FSH & $\begin{array}{l}2.75 \pm 1.6 \\
(N=92)\end{array}$ & $\begin{array}{l}2.78 \pm 1.26 \\
(N=151)\end{array}$ & $\begin{array}{l}\mathrm{I} .93 \pm 0.88 \\
(\mathrm{~N}=83)\end{array}$ & 0.01 & $\begin{array}{l}0.73 \pm 0.34 \\
(N=72)\end{array}$ & $\begin{array}{l}0.68 \pm 0.37 \\
(\mathrm{~N}=99)\end{array}$ & $\begin{array}{l}0.65 \pm 0.3 \\
(N=48)\end{array}$ & 0.66 \\
\hline $\mathrm{T}^{*}(\mathrm{nMol} / \mathrm{L})$ & $\begin{array}{l}2.90 \pm 1.11 \\
(\mathrm{~N}=92)\end{array}$ & $\begin{array}{l}3.01 \pm 1.32 \\
(\mathrm{~N}=151)\end{array}$ & $\begin{array}{l}2.11 \pm 0.9 \\
(N=83)\end{array}$ & 0.0045 & $\begin{array}{l}1.62 \pm 1.01 \\
(\mathrm{~N}=72)\end{array}$ & $\begin{array}{l}\mathrm{I} .03 \pm 0.73 \\
(\mathrm{~N}=99)\end{array}$ & $\begin{array}{l}\mathrm{I} .1 \mathrm{I} \pm 0.53 \\
(\mathrm{~N}=48)\end{array}$ & 0.0052 \\
\hline$E_{2}(p M o l / L)$ & $\begin{array}{l}259.7 \pm 128.72 \\
(N=92)\end{array}$ & $\begin{array}{l}223.49 \pm 109.96 \\
(N=15 I)\end{array}$ & $\begin{array}{l}190.46 \pm|| 4.8 \\
(N=83)\end{array}$ & 0.053 & $\begin{array}{l}|9| .52 \pm 152.7 \mid \\
(N=72)\end{array}$ & $\begin{array}{l}189.84 \pm 176.82 \\
(\mathrm{~N}=99)\end{array}$ & $\begin{array}{l}147.35 \pm 93.67 \\
(N=48)\end{array}$ & 0.25 \\
\hline
\end{tabular}

Note: a: $P=0.458$, genotypic distributions in women with PCOS vs those in the controls.

$P^{*}=0.000$ I (the total T values of women with PCOS vs those of controls) We failed to assay the hormone levels in several women with PCOS and controls. 
sample size in Cao's study was smaller, which may limit its representation of the colonia; second, the method chosen by Cao et al and us to detect the polymorphism may cause a misclassification of approximately 4 to $5 \%$ of the ID heterozygotes to the DD homozygotes [20]. We tried to correct this error. An additional PCR analysis is, therefore, needed for the confirmation of the DD genotypes obtained in the first standard PCR, including a new sense primer that is insertion-specific [20].

Although there were no significant differences in the distributions of the genotypes between the patients and the controls, we observed significant differences in the concentrations of testosterone among the three genotypes both in the patients and the controls (Table 3). By further analysis (Tukey-test), we found that, both in the patients and controls, the concentrations of testosterone in the DD genotype were higher than those in the II genotype $(P<$ 0.05 respectively). The DD genotype was associated with a higher level of ACE than either the ID or II genotype [8], which implicates that the increased lever of ACE may be associated with the higher concentration of testosterone. It also indicates that the I/D polymorphisms of the ACE gene may directly or indirectly contribute to the expression of the testosterone in the ovaries. There can be a number of explanations for the phenomenon: firstly, the ACE is associated with the angiogenesis of ovarian endothelium in vitro [3]. Although there's no report about ACE promoting the angiogenesis of ovarian endothelium in vivo in human, the ovary has higher blood supply than the other organs in the body $[21,22]$ and the majority of steroidogenic cells are in contact with at least one capillary [23]. If the higher level of ACE can stimulate the angiogenesis of ovarian endothelium in vivo and increase the blood supply, it may increase the supply of cholesterin which is the precursor of the steroid hormone. It is necessary to conduct further analysis to clarify the point. Secondly, the product of the ACE- Ang II is shown to inhibit LH-stimulated progesterone secretion from primary cultures of bovine corpora lutea cells [24] and from the midluteal phase bovine corpora lutea in an in vitro microdialysis system $[25,26]$. The reduced secretion of progesterone will stimulate the secretion of $\mathrm{LH}$ through negative feedback, which can explain the differential LH/FSH ratios in different genotypes of the patients. In addition, a higher level of testosterone can also increase the transformation of estrogen, which will further modulate the release of $\mathrm{LH}$ and FSH through either positive or negative feedback.

An interesting finding was that the total $\mathrm{T}$ concentrations between the I/D and D/D genotypes in the controls were different, whereas in the PCOS patients such concentrations between the I/D and I/I genotypes were different. One interpretation of this finding is that the I/D is a sus- ceptible genotype in the population of hyperandrogenism. In the controls, the I/D and I/I genotypes demonstrate no differences in the concentrations of $\mathrm{T}$. However, according to the prior studies, these two genotypes have different concentrations of ACE. Two possibilities may account for this observation: 1) the concentration of $\mathrm{T}$ is not associated with ACE; 2) ACE is not the key factor that influences the concentration of $\mathrm{T}$. However, in the PCOS patients the total T concentrations between the I/D and I/I genotypes were different, which cannot be explained if ACE is not associated with the concentration of $T$. The most probable reason may be that the $A C E \mathrm{I} / \mathrm{D}$ polymorphisms is only one of the co-factors that affects the etiopathogenisis of PCOS by interacting with other factors. The I/D genotype is more susceptible to hyperandrogenism.

\section{Conclusion}

The I/D polymorphisms in the ACE gene was not associated with the pathogenesis of PCOS. However, the polymorphisms were associated with the steroidogenesis in the ovary. This suggests that although the I/D polymorphisms in the ACE gene were not the key etiological factor, it may be associated with the aggravated clinical manifestations of PCOS.

\section{Abbreviations}

I/D Polymorphism: Insertion/Deletion Polymorphism; ACE: Angiotensin-converting Enzyme; RAS: the reninangiotensin system; PCOS: Polycystic Ovary Syndrome; LH: luteinizing hormone; FSH: follicle-stimulating hormone; E2: estradiol; BMI: body mass index (body weight in kilograms divided by square of height in meters); AAM: age at menarche; T: testosterone; P: progesterone; RIA: radio-immunity assay; PCR: polymerase chain reaction; PCO: polycystic ovarian; Ang II: Angiotensin II.

\section{Competing interests}

The authors declare that they have no competing interests.

\section{Authors' contributions}

JS, HF, FL and CY carried out DNA extraction and the molecular genetics experiments. JS, LY, YW performed the statistical analysis and drafted the manuscript. YC, XW, $\mathrm{HF}$ and SH participated in sample collection. LY participated in the designing of the study and helped to carry out the molecular genetics experiments. YW and YC conceived and directed the study, and helped to draft the manuscript. All authors read and approved the final version of the manuscript.

\section{Acknowledgements}

This study was supported by the National Naturel Science Foundation of China (30672228). 


\section{References}

I. Yoshimura Y: The Ovarian Renin-Angiotensin System in Reproductive Physiology, Frontiers in neuroend ocrinology. Front Neuroendocrinol 1997, I 8(3):247-29I.

2. van Sande ME, Scharpé SL, Neels HM, Van Camp KO: Distribution of angiotensin converting enzyme in human tissues. Clin Chim Acta 1985, I47(3):255-60.

3. Plend J, Neumiiller C, Vollmar A, Auerbach R, Sinowatz F: Isolation and characterization of endothelial cells from different organs of fetal pigs. Anat Embryol 1996, I 94:445-456.

4. Stefanello JR, Barreta MH, Porciuncula PM, Arruda JN, Oliveira JF, Oliveira MA, Gonçalves PB: Effect of angiotensin II with follicle cells and insulin-like growth factor-I or insulin on bovine oocyte maturation and embryo development. Theriogenology 2006, 66(9):2068-2076.

5. Giometti IC, Bertagnolli AC, Ornes RC, da Costa LF, Carambula SF, Reis AM, de Oliveira JF, Emanuelli IP, Gonçalves PB: Angiotensin II reverses the inhibitory action produced by theca cells on bovine oocyte nuclear maturation. Theriogenology 2005, 63(4): $1014-25$.

6. Acosta TJ, Berisha B, Ozawa T, Sato K, Schams D, Miyamoto A: Evidence for a local endothelin-angiotensin-atrial natriuretic peptide systemin bovine mature follicles in vitro: effects on steroid hormones and prostaglandin secretion. Biol Reprod |999, 6 |(6): |4|9-25.

7. Nielsen AH, Hagemann A, Svenstrup B, Nielsen J, Poulsen K: Angiotensin II receptor density in bovine ovarian follicles relates to tissue renin and follicular size. Clin Exp Pharmacol Physiol 1994 2 I (6):463-9.

8. Rigat B, Hubert C, Alhenc-Gelas F, Cambien F, Corvol P, Soubrier F: An insertion/deletion polymorphism in the angiotensin Iconverting enzyme gene accounting for half the variance of serum enzyme levels. J Clin Invest 1990, 86: I 343- I 346.

9. Azziz R, Carmina E, Dewailly D, Diamanti-Kandarakis E, et al.: Position statement: Criteria for defining polycystic ovary syndrome as a predominantly hyperandrogenic syndrome: An Androgen Excess Society guideline. J Clin Endocrinol Metab 2006 91:4237-4245.

10. Diamanti-Kandarakis E: Polycystic ovarian syndrome: pathophysiology, molecular aspects and clinical implications. Expert Reviews in molecular medicine 2008, I 0(2):e3.

II. Cho LW, Randeva HS, Atkin SL: Cardiometabolic aspects of polycystic ovarian syndrome. Vasc Health Risk Manag 2007, 3(I):55-63.

12. Diamanti-Kandarakis E, Piperi C, Spina J, Argyrakopoulou G, Papanastasiou L, Bergiele A, Panidis D: Polycystic ovary syndrome: the influence of environmental and genetic factors. Hormones (Athens) 2006, 5(I): I7-34.

13. So WY, Ma RCW, Ozaki R, Tong PCY, Ng MCY, Ho CS, Lam CWK, Chow CC, Chan WB, Kong APS, Chan JCN: Angiotensin-converting enzyme (ACE) inhibition in type 2 , diabetic patients interaction with ACE insertion/deletion polymorphism. Kidney International 2006, 69:|438-|443.

14. Ferrara N, Frantz G, LeCouter J, Dillard-Telm L, Pham T, Draksharapu A, Giordano T, Peale F: Differential Expression of the Angiogenic Factor Genes Vascular Endothelial Growth Factor (VEGF) and Endocrine Gland-Derived VEGF in Normal and Polycystic Human Ovaries. Am J Pathol 2003, I 62(6): |88|-|893.

15. Ferreira R, Oliveira JF, Fernandes R, Moraes JF, Gonçalves PB: The role of angiotensin II in the early stages of bovine ovulation. Reproduction 2007, I34(5):7I3-9.

16. The Rotterdam ESHRE/ASRM-sponsored PCOS Consensus Workshop Group: Revised 2003 consensus on diagnostic criteria and long-term health risks related to polycystic ovary syndrome (PCOS). Hum Reprod 2004, I 9(I):4I-47

17. Rigat B, Hubert C, Corvol P, Soubrier F: PCR detection of the insertion/deletion polymorphism of the human angiotensin converting enzyme gene (DCPI) (dipeptidyl carboxypeptidase I). Nucleic Acids Res 1992, 20(6): | 433.

18. Cao Y, Zhuang G: Study on the Relationship between Polymorphism of the Angiotensin - converting - enzyme Gene and Polycystic Ovarian Syndrome Chinese. Journal of Practical Gynecology and Obstetrics 1999, I 5(1 2):726-728.

19. Cao Y, Wang Y, Zhou P, et al.: Relationship between ACE gene polymorphism and the renin - angiotensin system in PCOS patients. Chinese Journal of Practical Gynecology and Obstetrics 2002, I 8(I I):665-666.

20. Shanmugam V, Sell KW, Saha BK: Mistyping ACE heterozygotes. PCR Methods Appl 1993, 3:120-121.

21. Bruce NW, Moor RM: Capillary blood flow to ovarian follicles, stroma and corpora lutea of anaesthetized sheep. I Reprod Fertil 1976, 46(2):299-304

22. Wiltbank MC, Dysko RC, Gallagher KP, Keyes PL: Relationship between blood flow and steroidogenesis in the rabbit corpus luteum. J Reprod Fertil I988, 84(2):513-20.

23. Reynolds LP, Killilea SD, Redmer DA: Angiogenesis in the female reproductive system. FASEB J 1992, 6(3):886-92.

24. Stirling D, Magness RR, Stone R, Waterman MR, Simpson ER: Angiotensin II inhibits luteinizing hormone-stimulated cholesterol side chain cleavage expression and stimulates basic fibroblast growth factor expression in bovine luteal cells in primary culture. J Biol Chem 1990, 265(I):5-8.

25. Schams D, Berisha B, Neuvians T, Amselgruber W, Kraetzl WD: Real-time changes of the local vasoactive peptide systems (angiotensin, endothelin) in the bovine corpus luteum after induced luteal regression. Mol Reprod Dev 2003, 65(I):57-66.

26. Hayashi K, Miyamoto A: Angiotensin II interacts with prostaglandin F2 alpha and endothelin-I as a local luteolytic factor in the bovine corpus luteum in vitro. Biol Reprod 1999 , 60(5): I 104-9.

\section{Pre-publication history}

The pre-publication history for this paper can be accessed here:

http://www.biomedcentral.com/1471-2350/10/64/pre pub
Publish with Biomed Central and every scientist can read your work free of charge

"BioMed Central will be the most significant development for disseminating the results of biomedical research in our lifetime. "

Sir Paul Nurse, Cancer Research UK

Your research papers will be:

- available free of charge to the entire biomedical community

- peer reviewed and published immediately upon acceptance

- cited in PubMed and archived on PubMed Central

- yours - you keep the copyright
BioMedcentral 